\title{
Anterior temporal white matter lesions in adult-form myotonic dystrophy type 1
}

Lesões temporais anteriores da substância branca na forma adulta da distrofia miotônica tipo 1

Leonardo Ferreira Caixeta ${ }^{1}$, Giane Souza Reis ${ }^{2}$, Ana Caroline Marques Vilela ${ }^{3}$

A 57-year-old woman presented with a 4-years history of progressive weakness, distal muscular atrophy and myotonia in left hand (Figure 1). Her electromyography had a myotonic pattern. Patient was first diagnosed as paraneoplasic limbic encephalitis based on her brain MRI (Figure 2). Diagnosis was genetically confirmed for myotonic dystrophy type 1 (DM1).
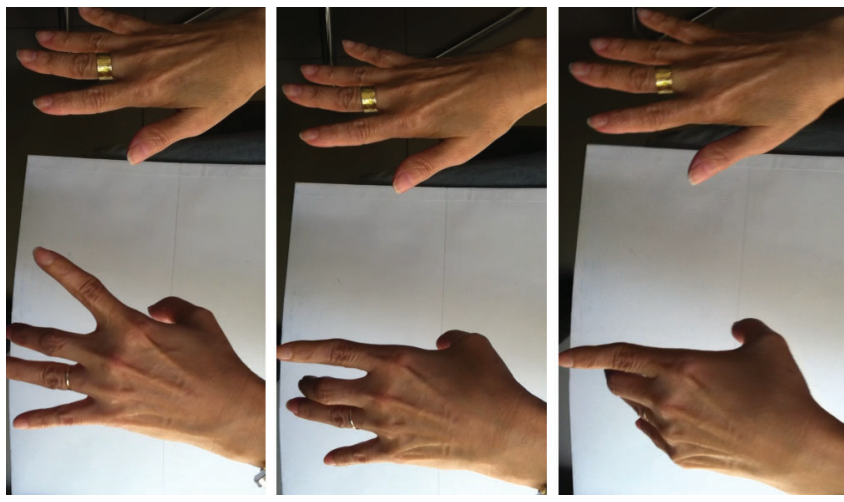

Figure 1. Dystrophy and sequence of myotonia in left hand.
DM1 or Steinert's disease is an autosomal-dominant disorder characterized by muscle weakness and unusual features, compared with other dystrophies, including myotonia, anticipation, and multiple organ involvement ${ }^{1,2}$. Anterior temporal lobe subcortical white matter lesions are described in DM1, but not in DM2 patients ${ }^{3}$. Limbic encephalitis and CADASIL are the most important imaging differential diagnosis.
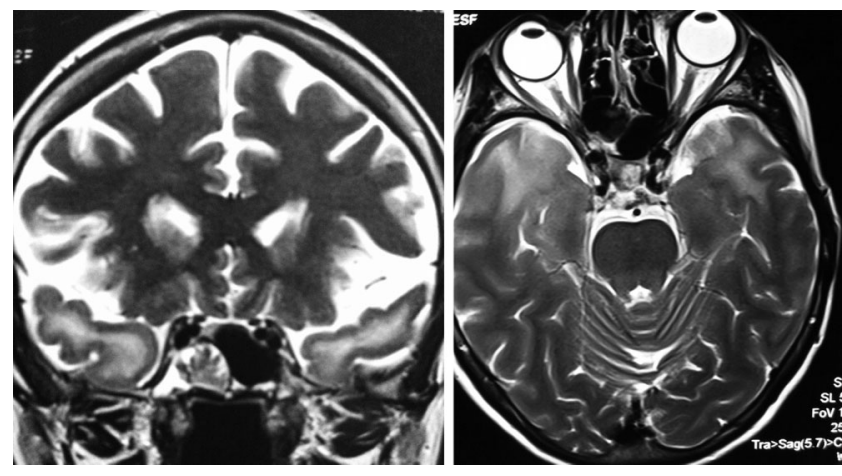

Figure 2. MRI (T2 weight coronal and axial slices) showing bilateral anterior temporal hypersignal in our case. Notice that mesial temporo-limbic structures are not affected.

References

1. Meola G, Sansone V. Cerebral involvement in myotonic dystrophies. Muscle Nerve. 2007;36(3):294-306. http://dx.doi.org/10.1002/mus.20800

2. Machuca-Tzili L, Brook D, Hilton-Jones D. Clinical and molecular aspects of the myotonic dystrophies: a review. Muscle Nerve 2005;32(1):1-18. http://dx.doi.org/10.1002/mus.20301
3. Kornblum C, Reul J, Kress W, Grothe C, Amanatidis N, Klockgether T et al. Cranial magnetic resonance imaging in genetically proven myotonic dystrophy type 1 and 2. J Neurol. 2004;251(6):710-4. http:// 10.1007/s00415-004-0408-1

${ }^{1}$ Departamento de Neurologia, Faculdade de Medicina, Universidade Federal de Goiás, Goiânia GO, Brazil;

${ }^{2}$ Departamento de Neurologia, Universidade Federal de Goiás, Goiânia GO, Brazil;

${ }^{3}$ Universidade Federal de Goiás, Goiânia GO, Brazil.

Correspondence: Leonardo Ferreira Caixeta; Avenida Cristo Rei 626, Setor Jaó; 74674-290 Goiânia GO, Brasil; E-mail: leonardocaixeta1@gmail.com Conflict of interest: There is no conflict of interest to declare.

Received 02 April 2014; Received in final form 22 July 2014; Accepted 01 August 2014. 